exceed $100 / \mathrm{cm}^{3}$. The corresponding rate of production of salt nuclei at the sea surface is estimated to be $1,000 / \mathrm{cm}^{2}$ sec. It was therefore inferred that sea-spray contributes perhaps only one-fifth of the nuclei involved in cloud formation, the majority being the products of combustion.

A paper by $K$. Isono (Tokyo) described how the residues of cloud droplets collected on the summit of a mountain $150 \mathrm{~km}$. from the sea have been examined under the electron microscope and their nature determined by electron diffraction. Most of the nuclei are less than $1 \mu$ in diameter; about 30 per cent consisted of sodium chloride, 20 per cent of unidentified soluble particles, and 50 per cent of insoluble particles-probably combustion products.

H. Dessens (France) has established that giant hygroscopic nuclei $(r>10 \mu)$ exist in concentrations of at least $100 / \mathrm{m}^{3}$ in the equatorial forests of the Belgian Congo, while nuclei of radius less than $0.4 \mu$ are present in much higher concentrations. No sodium chloride crystals have been identified among the giant particles, the most important source probably being the savannah fires. M. Dessens also described some very interesting experiments in which he has been able to produce quite large cumulus clouds in an otherwise clear sky by the burning of vegetation.

Other aspects of the subject were represented by contributions from H. W. Georgii (Frankfurt) on the measurement of the turbulent diffusion of aerosols near the ground, and by F. Volz (Mainz) on the production of dusts and their spatial distribution in the atmosphere.

Although a good deal of the material presented was not entirely new, the conference produced much vigorous and good-humoured discussion and some clarification and agreement as to what are the important problems. These include the collection and identification of the large and giant nuclei over both land and sea at different levels in the atmosphere, and investigation of the processes by which they are produced and transported.

The organizing committee is to be congratulated on the excellence of the arrangements in ideal surroundings. The proceedings of the conference will be published in a special issue of Geofisica Pura $e$ Applicata. It is expected that the next symposium will be held in Britain in 1958.

B. J. MASON

\section{WORLD TELECOMMUNICATION}

7 HE major part of the inaugural address as 1 president of the Institution of Electrical Fngineers, delivered by Sir Gordon Radley, director general of the Post Office, on October 4, was devoted to a consideration of world telecommunication, a subject particularly topical in view of the recent opening to traffic of the first trans-Atlantic telephone cable. The practical realization of inter-continental multi-channel telephone communication by submarine cable is, in Sir Gordon's view, revolutionary in its possibilities, because the traffic capacities of such cables are likely to exceed the existing demand for telegraph and telephone facilities on their routes. It is important to appreciate that it is the advent of the submerged repeater or amplifier which has rendered long-distance submarine telephony practicable. The attenuation of the NewfoundlandScotland section of the trans-Atlantic telephone cable at $164 \mathrm{kc} . / \mathrm{s}$. is approximately $1.6 \mathrm{db}$. per nautical mile, and an input power at the enormous level of $100 \mathrm{MW}$. would not be detectable by the most sensitive galvanometer at a distance greater than 150 miles. In the cable, repeaters are inserted every 38 miles, and the gain of each of these is $65 \mathrm{db}$., representing a power amplification greater than $10^{6}$. On this basis multi-channel telephony is practicable on the longest submarine circuits.

The trans-Atlantic cable circuit utilizes, for the longest ocean link, separate cables for the two directions of transmission. 'The 'one-way' repeaters in these cables are accommodated in flexible housings only a little larger in diameter than the cable itself. These repeaters can be passed over the laying gear of the cable ship, and laying can be carried on continuously as with a conventional cable. The alternative arrangement of two-way transmission on a single cable requires a considerably greater space in the repeater housing to accommodate the additional filters and more complex circuits. The rigid housings for these repeaters require special handling in laying and considerably complicate that operation. The devising of means whereby the laying of such rigid repeaters could be carried out as part of a continuous cable-laying operation is, in fact, an immediate task of great importance.

Sir Gordon devoted considerable attention to the relative costs of single- and double-cable schemes, illustrating the matter by curves showing the estimated capital cost and annual cost per telephone circuit for cables 2,000 miles long, plotted to a base of total band-width transmitted in each direction. The cost per circuit is shown to decrease rapidly as the band-width or total capacity of the system is increased. It is thus economically advantageous to include in one cable, or pair of cables, all required facilities, telegraphy, telephony and---ultimately-television.

In regard to the economics of telephone-cable schemes on the main cable routes of the world, there appears to be a marked distinction between the North Atlantic route and all others. Sir Gordon remarked that the impetus to the growth of traffic between Western Europe and North America given by the 1956 telephone cable might well produce an early demand for a second cable of the greatest capacity technically possible. Eighty circuits in a single-cable system or two hundred in a twin-cable system was an objective only just beyond the limits at present imposed by repeater spacing and cable diameter, and either system, if reasonably loaded with traffic at the present call-rates, would be profitable.

On other world routes the economic prospects are less promising. Circuits to Australia and New Zealand, 12,000 miles long, might have a volume of traffic between 5 per cent and 10 per cent of the traffic with North America. It is clear that, for so great a distance with a small group of circuits, cable could not be competitive on cost with radio. On the other hand, experience of the propagation of high-frequency waves has shown that satisfactory radio communication cannot be maintained continuously over such difficult routes as the North Atlantic, or to the Antipodes.

It thus appears that the challenge to the communication engineer is that of providing submarine cable facilities on the main trunk routes of the world on a similar scale to that which has become estab. lished practice on land. This challenge is of very direct concern to British manufacturers, for Britain has a unique tradition of submarine cable manufacture 
and has an exceptionally large manufacturing capacity for this class of equipment.

In relation to inland telecommunication, Sir Gordon stated that "electronic techniques are likely to revolutionize the art of telephone switching within the foreseeable future". Fully electronic switching systems are being developed along two distinct lines, one in which gas diodes or other corresponding devices are used in a 'space multiplex' to connect speech paths, and the other in which time-division multiplex operation enables individual subscribers to communicate. The production cost of an electronic exchange is likely to be less than that of the corresponding mechanical equipment, and it is thought that maintenance costs should also be reduced.

A new facility is planned for the trunk telephone network of Great Britain in the form of subscriberdialling of long-distance calls. To render this practicable, it is necessary to have a nation-wide number scheme, and the system is being planned on the basis of 20 million subscribers connected to 8,000 telephon $\Theta$ exchanges.

In the trunk network, co-axial cables carrying 600 speech channels are in operation between the main centres of population, and similar plant modified to transmit a slightly wider band of frequencies is used for television. It is proposed, on these co-axial cable routes, to reduce the spacing between repeater stations to three miles, if sufficient traffic offers, as this would enable each tube of the cable to carry 1,000 telephone channels plus a 405-line television channel. The micro-wave radio relay system planned for Britain is capable of carrying 600 channels of telephony, or one television channel..

In his concluding remarks, Sir Gordon mentioned that he had not followed the example of his predeces. sors in office during the past few years as he had made no reference to the great need in Britain for more technologists, or to the means of training them. $\mathrm{He}$ had, however, described a few of the problems and projects which at present are challenging the ingenuity and energy of the telecommunication engineer, and he hoped that in so doing he might have kindled here and there a spark of interest and enthusiasm for work in a field of endeavour where much can be done to serve the nation, the Common. wealth, and the world at large.

J. Greig

\section{CITY AND GUILDS OF LONDON INSTITUTE}

$T$ HE year 1955 was a memorable one for the City and Guilds of London Institute in that the entries for the Institute's examinations exceeded a hundred thousand for the first time. From 1878 until 1955 more than $1 \frac{1}{2}$ million people have entered for the Institute's examinations, and the fact that half a million of these have done so within the past six years emphasizes how great has been the expansion of technical education. During the year many new subjects have been introduced to meet new needs, and a large number of existing subjects have been carefully reviewed and where necessary the syllabuses have been modified.

The Institute regularly surveys its schemes not merely as separate subjects but also in their relation. ship to each other and in relation to their place in the national economy. As an example, some account is given in the annual report of those subjects which have a particular bearing on the proper use of the nation's fuel resources and the contribution which appropriate courses of study can make to industrial fuel efficiency.

The Associated Examining Board for the General Certificate of Education, for which the Institute has undertaken the administrative and financial responsibility in the initial years, has now been successfully launched. In the first examination, held in the summer of 1955, nearly five thousand papers were taken in more than seventy subjects at ordinary and advanced levels, and the entry figure has been more than doubled in the summer exam. ination of 1956. Omissions in the list of subjects offered by the Board are continually being made good, and the new subjects recently approved include commercial subjects (including shorthand and typewriting) at ordinary level, music at ordinary level, and dress at ordinary and advanced levels.

The report also contains an account of the way the Institute has been re-organized to meet the challenge of changing times.

\section{NITROGEN METABOLISM AS AFFECTED BY POTASSIUM DEFICIENCY}

SOME new and interesting aspects of nitrogen $\checkmark$ metabolism in barley, especially as it is affected by potassium deficiency, have been investigated by R. G. Coleman and F. J. Richards (Ann. Bot., N.S., $20,79,393 ; 1956)$. Barley was grown in water and sand culture, using a variety of nutrient solutions, the most important variable being potassium supply. It was observed that the diamine putrescine, which is not normally found in this plant in appreciable amounts, was present in potassium-deficient seedlings and that it accumulated during their growth. Its maximum accumulation coincided with the development of the severe symptoms associated with advanced deficiency. Putrescine occurs at an varlier stage in potassium-deficient plants, the nitrate and phosphate of which are supplied as ammonium salts, than in those to which the corresponding calcium salts are given. It is found less abundantly in the roots than in the tops. It is absent from protein hydrolysates.

These investigators have also shown that a leaf necrosis characteristic of potassium deficiency can be induced by feeding putrescine to barley having a high potassium status; after prolonged feeding the appearance of such plants suggested severe potassium starvation. The putrescine is slowly utilized, and at the same time an unidentified substance is produced. It is stated that what seems to be the same substance appears in quantity in high-potassium red clover during the course of rapid utilization of administered putrescine. It also occurs naturally in potassiumdeficient red clover. When potassium is supplied to potassium-deficient barley in which putrescine has accurnulated, the amine soon disappears. Application of either rubidium or sodium also leads to a reduction in putrescine, though to a lesser extent, rubidium being the more effective element. Under conditions of extreme potassium-deficiency, wheat and red clover also accumulate putrescine. The free aminoacid composition of the wheat then bears a striking resemblance to that of deficient barley. 